\title{
Impact of diabetes and metformin use on B-vitamin status and cognitive function in older Irish adults: results of the TUDA cohort study
}

\author{
K. Porter ${ }^{1}$, C.F. Hughes ${ }^{1}$, L. Hoey ${ }^{1}$, M. Ward ${ }^{1}$, A. Molloy ${ }^{2}$, C. Cunningham ${ }^{3}$, MC. Casey ${ }^{3}$, \\ J.J. Strain ${ }^{1}$, M. O'Kane ${ }^{4}$, F. Tracey ${ }^{5}$, K. McCarroll ${ }^{3}$, A McCann ${ }^{1}$ and H. McNulty ${ }^{1}$ \\ ${ }^{1}$ Northern Ireland Centre for Food and Health, Ulster University, Coleraine, BT52 1SA, \\ ${ }^{2}$ Institute of Molecular Medicine, School of Medicine, Trinity College, Dublin 2, Ireland, \\ ${ }^{3}$ Mercers Institute for Research on Ageing, St James's Hospital, Dublin, Ireland, \\ ${ }^{4}$ Clincial Chemistry Laboratory, Western Health and Social Care Trust, Altnagelvin Hospital, Londonderry, Northern \\ Ireland and \\ ${ }^{5}$ Causeway Hospital, Northern Health and Social Care Trust, Coleraine, Northern Ireland
}

Diabetes is estimated to affect 422 million people worldwide, and this is predicted to double by $2035^{(1)}$. Diabetes and the use of metformin has been associated with lower status of B12, but no study to date has considered the relationship between diabetes and metformin with all the relevant B-vitamins involved in one-carbon metabolism. This is relevant, especially in older age, because low status of vitamin B12, folate and the metabolically related B vitamins (vitamin B6 and riboflavin) have been independently linked with cognitive dysfunction ${ }^{(2)}$, an emerging co-morbidity of diabetes ${ }^{(3)}$. The aim of this investigation was to examine whether diabetes and/or metformin use was associated with adverse effects on vitamin B12 and the metabolically related B vitamins, and to examine the relationship with cognitive dysfunction.

Participants from the Trinity, Ulster, Department of Agriculture (TUDA) Ageing Cohort Study ( $\geqslant 60$ years, $\mathrm{n} 4904$ ) were classified as: normoglycaemic $(n 3563)$ or hyperglycaemic, either with $(n 315)$ or without $(n$ 1026) metformin treatment, based on glycosylated haemoglobin $\left(\mathrm{HbA}_{1} \mathrm{c}\right)$ level $\geqslant 42 \mathrm{mmol} / \mathrm{mol}$. Cognitive performance was assessed using the Repeatable Battery for the Assessment of Neuropsychological Status (RBANS) and the Frontal Assessment Battery (FAB). Hyperglycaemia was associated with a greater risk of vitamin B6 deficiency while metformin use exacerbated this risk and was also associated with an increased risk of vitamin B12 deficiency; the latter effect was not seen in hyperglycaemia without metformin use (Table). No significant associations were seen for folate or riboflavin and hyperglycaemia or metformin use. Hyperglycaemia was also associated with an increased risk of cognitive dysfunction, particularly among participants aged 60-75 years, as measured by Frontal Assessment Battery, with (OR: 1.67; $95 \%$ CI 1.15-2.42; $P$ 0.007) or without (OR: $1.38 ; 95 \%$ CI 1.11-1.73; $P$ 0.004) metformin use.

\begin{tabular}{|c|c|c|c|c|c|c|}
\hline & \multicolumn{3}{|c|}{ Vitamin B12 deficiency $^{1}$} & \multicolumn{3}{|c|}{ Vitamin B6 deficiency $^{1}$} \\
\hline & $\overline{\mathrm{OR}}$ & $95 \% \mathrm{CI}$ & $P$ value & $\overline{\mathrm{OR}}$ & $95 \% \mathrm{CI}$ & $P$ value \\
\hline Normoglycaemic (Reference categor) & & & & & & \\
\hline $\begin{array}{l}\text { Hyperglycaemic } \\
\text { Hyperglycaemic and on metformin }\end{array}$ & $\begin{array}{l}0.943 \\
1.517\end{array}$ & $\begin{array}{l}0.789-1.126 \\
1 \cdot 119-2.056\end{array}$ & $\begin{array}{l}0.516 \\
0.007\end{array}$ & $\begin{array}{l}1.246 \\
1.568\end{array}$ & $\begin{array}{l}1.014-1.531 \\
1.093-2.249\end{array}$ & $\begin{array}{l}0.036 \\
0.014\end{array}$ \\
\hline
\end{tabular}

Binary logistic regression was performed with adjustment for age (years), gender, BMI, creatinine, B-vitamin supplement usage, and relevant drug use (proton pump inhibitors, H2-antagonists and other anti-diabetic drugs). ${ }^{1}$ Low status of B12 is serum B12 $\leqslant 185 \mathrm{pmol} / \mathrm{L}$ and vitamin B6 is plasma pyridoxal 5-phosphate $<30.0 \mathrm{nmol} / \mathrm{L}$. Abbreviations: CI, Confidence Interval; OR, Odds Ratio.

These results show that older adults with or at-risk of diabetes $\left(\mathrm{HbA}_{1} \mathrm{c}\right.$ level $\left.\geqslant 42 \mathrm{mmol} / \mathrm{mol}\right)$ are at a significantly greater risk of B-vitamin deficiency and have poorer cognitive health, especially if taking metformin. The promotion of regular fortified foods such as breakfast cereals as a source of bioavailable B-vitamins may be beneficial in this at-risk group. Further research is warranted to explore the relationship between diabetes, metformin, B-vitamin status and cognitive health in ageing.

1. Diabetes UK. (2015) Facts and stats. London: Diabetes UK.

2. Smith D, Refsum H (2016) Annual Review of Nutrition 36, 211-39.

3. Biessels G, Staekenborg S, Brunner E, et al. (2006) Lancet Neurology 5, 64-74. 